\section{INTELLIGENT AIR CLEANERS}

IQ Air's Swiss-made range of air cleaners achieve what is known as Hyper HEPA performance, which means the whole machine has been classified as HEPA standard, not just the filter. These filters are designed to remove $99.7 \%$ of all airborne pollutants with an efficiency of $0.3 \mu \mathrm{m}$. IQ Air has the advantage of intelligent individual filter change sensors, which enables you to change each filter individually as it becomes used.

The Dental Series Air Purifiers are ideal for the following applications: microbial control; bacteria and viruses; fungal/mould spores; oral Volatile
Sulphur Compounds (VSC) that cause malodours; drilled aerosol control; dispersed tissue and fluids; dispersed viruses and bacteria; mercury control; mercury vapours; disinfectant control; formaldehyde; alcohol; general particle control; powder particles; polishing particles; and allergens.

Reader response number 53

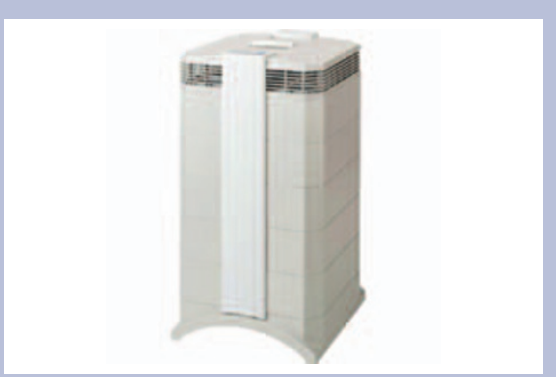

\section{STERILE KITS FOR ALL}

Classic from UnoDent has launched its own range of sterile Surgical/Implant Kits - suitable for those operating in general dentistry and in implantology/ oral surgery. The Classic range from UnoDent is a selection of everyday dental products designed to give good quality at excellent value for money.

These new sterile kits not only meet rigorous safety standards, but are also very cost effective and have been produced as a result of six months' procedure research, helping you remain compliant.

Classic offers a choice of three kits: Complete Drape (COP405), Standard Drape Kit (COP400) and a Surgical Gown Kit (COP410) - all are available to order now from The Dental Directory.

Reader response number 56

\section{LEARN TO SATISFY IN LEUVEN}

Lunch and Learn sessions to ensure your team is fully aware of the latest legislation with regards to the supply of compressed air in the dental surgery.

Available during your lunch hour or at the end of the working day, DentalAir. com's representative will teach staff how to minimise the risks associated with compressed air and vacuum systems. Attendees will leave with a clear understanding of the implications regarding health and safety and the NHS for the use of compressed air in the surgery. Reader response number 54

HTM 01-05 guidelines (subject to local approval), regardless of size limitation.

Henry Schein Minerva's understanding of instrument flow through the cleaning cycle from surgery to sterilisation room means they have the skills to manage your HTM 01-05 project from start to finish. From complete project management including local decontamination layouts from under $£ 100$ per month (subject to specification and room size) to providing and installing tailor-made cabinetry and equipment, Henry Schein Minerva can help you create the perfect HTM 01-05 compliant surgery, with minimal stress and disruption. Reader response number 55
As GC value training so highly, the company has invested heavily and is delighted to announce a new series of courses for 2011 that will be taking place at the GC Campus - meeting and education centre based at the European headquarters in Leuven, Belgium.

GC has recently launched an improved composite system with G-aenial. The hands-on training courses have been designed for dentists to learn how to place the very best composite using a combination of materials. After analysing the structure of the surrounding teeth, simple steps are used to create the perfect restoration using G-aenial. Even monochromatic restorations look fabulous due to the unique chameleon effect of the composite. Together with materials from the Gradia Lab kit that can be used in the mouth, you will learn how to create the most satisfying restorations for you and your patients.

For more advanced users there is an additional course that adopts a theoretical and practical approach to this most sophisticated direct composite system. Spaces on these two-day courses are limited for maximum personalisation. Reader response number 57 